\title{
Soaring Demand on Public Health Innovation through Digitalization due to Pandemic, are Tech Stocks worth Investing?
}

\author{
Jennifer A. Carag \\ San Sebastian College Recoletos - Manila, Philippines
}

\begin{abstract}
Despite optimism, COVID-19 pandemic still emerges as a challenge to the economy and public health worldwide. Authorities have taken a variety of measures focusing on the control of the spread of the fatal disease. With no available cure and high transmissibility rate, containment, testing, social distancing, lockdowns, and epidemiological investigation are practiced globally. Digital innovation comes into play from the technology industry just like software applications, artificial intelligence, and the like as a supplement to conventional practices. Technology has played a pivotal role in the disease investigation process and in preventing further outbreaks. With all the uncertainty in the market, economy, and public health, how lucrative is investing in Tech Stocks nowadays?
\end{abstract}

Keywords: Digital, Innovation, Technology, Stock Market, Stocks, Pandemic.

\section{INTRODUCTION}

Early 2020, the World Health Organization (WHO) declared the outbreak of a pneumonia-like disease called COVID-19 virus, as a global pandemic. With no effective vaccine discovered and its high fatality rate, the linchpin of handling the pandemic has been containment, mitigation 1 , and contact-tracing. Despite all-out efforts, there have been varying degrees of success in countries all over the world.

Public health innovation through digitalization has hastily emerged amidst a health crisis. Technology companies see the pandemic as an opportunity. The outbreak has increased leverage of digital technologies in healthcare. One of these is digitalizing the contact-tracing process through software applications. It is an effective strategy in breaking the chain of disease transmission among people by facilitating the manual process of monitoring exposed individuals and those at high risk of infecting others. Contact-tracing is a core disease control measure that has been exercised by public health

1 A novel coronavirus from patients with pneumonia in China, 2019. N Engl J Med. 2020; 382: 727-733 authorities globally. Software applications developed have made the process cost effective and has saved people from potentially being stigmatized and keeping their privacy pristine.

Global health experts believe that technology can accelerate COVID-19 response strategies through digital health optimization. Advanced countries integrated digital technology into government-coordinated containment and mitigation processes such as monitoring/surveillance, contact tracing, lock downs and quarantines. In addition, chatbots or Artificial Intelligence (AI) platforms were developed to guide users by providing clarity to their COVID-19 related queries or concerns. The innovation that Technology Industries has to offer is too vast and broad, making the tech sector well liked and marketable.

\section{STATEMENT OF THE PROBLEM}

The unprecedented economic needs caused by COVID-19 pandemic outbreak serve as a driving force to develop and adopt new digital technologies especially in healthcare at scale and speed. The world has become increasingly dependent on digitalization and looking forward to even greater reliance on technology in the post pandemic. As a result, the technology sector is in demand and considered a high performing sector in the stock market. The tech-heavy NASDAQ has gained about $20 \%$ return this year to date.

No doubt that the pandemic has drastically changed our way of life. Nationwide lockdown, and strict quarantine/isolation protocols has affected our economy. Stock Markets continue to remain down and dip lower resulting in some investors selling off their stocks due to fear of cash loss. Experts say that a pandemic should not scare anyone in investing in the stock market especially since it has caused prices to go down. There is no better time to start investing than now.

Technology is also known for its extreme competition and fleeting obsolescence. Given the circumstances added by the fickleness in the economy globally, would investing in Tech Stocks worthwhile? 


\section{CAUSES OF THE PROBLEM}

Technology sector looks like a big fish in a small pond. It is a huge investment opportunity with high risk but offers high reward. With all the hype, there are increasing risks that an investor may need to consider such as crowding, margin pressure, valuations, and obsolescence risk. Digitalization may sound compelling but investors need to consider the path of economic recovery post pandemic.

\section{COURSES OF ACTION}

No sector in the modern economy that technology has not touched. The idea of investing in tech stocks can be appealing to those who aim to achieve quick major gains. There are 3 things that an investor must consider before investing.

Thinking ahead - Tech stocks show off higher premiums than almost any other market category especially during pandemic. As an investor, researching and practicing due diligence plays an important role in successful stock ventures, mitigating risk and discovering your risk appetite. Having indepth knowledge on details of technology products like software, collaboration applications, automation programs, microchips, hardware, semiconductors, etc., its advantages, and disadvantages pay off. Technology's shifting nature made itself prone to obsolescence risk. It is vital to evaluate how technological changes impact portfolio holdings to see which types of asset, securities or sectors face higher risk of obsolescence from rowdy technologies and where the next opportunity lies.

Consider Hedging - Market Volatility plays a crucial role in decision making on investment repositioning and as to when to pull focus. Some experts suggest hedging higher growth tech stocks with recurring exposed stocks to offset any risks. Knowing your risk appetite reminds the basic rule in investing - you only invest what you are comfortable to lose.

Getting Ready to Techlash - Investors must brace for impact on tech lashes relating to geopolitical issues, tax implications, copyright, privacy and security concerns, etc. Authorities have not finalized the regulations surrounding it, making it more challenging as technology firms continue to self-regulate them rather than wait for the imposed definite regulations causing conflicts.

\section{CONCLUSION}

The world is in the middle of a generational shift from basic to advanced, keypads to touch screens, desktop software to cloud-based Software-as-a-Service products (SaaS), etc. Investors' love and hate affair with tech stocks shall continue even in the post pandemic. A record breaking NASDAQ composite index was recently recorded because of consumerfacing tech companies that lead the digital landscape during this pandemic. Indeed, investing in tech stocks is exciting and monumental. A good tech stock is the one that trades at a reasonable valuation given its growth prospects. It remains and continues to be compelling for investors.

\section{RECOMMENDATION}

Considering the antifragility of the technology firms in the market, it would make sense, as an investor, to widen your circle of competence to reduce exposure through adding other sectors such as financials, industrials, etc. Every investor should keep in mind to only invest if you are $100 \%$ comfortable with losing, especially in times of pandemic uncertainty. The higher the risk, the higher the reward. The battle of the unknown and unknowable is not yet over. Recent reports say that the virus is continually mutating to a more stringent and stronger strain. No one can tell when this will be over but it does not mean our world has to stop. The world may expect new business models and innovators to emerge fundamentally to support the shift of our life to online. A successful investor nowadays, is equipped, knowledgeable, and a good risk evaluator.

\section{REFERENCES}

[1] A novel coronavirus from patients with pneumonia in China, 2019. N Engl J Med. 2020; 382: 727-733.

[2] COVID-19 fear index: does it matter for stock market returns?, Sowmya Subramaniam et al., Review of Behavioral Finance, 2021.

[3] Aruoba, S.B., Diebold, F.X. and Scotti, C. (2009), "Real-time measurement of business conditions", Journal of Business and Economic Statistics, Vol. 27, pp. 417-27.

[4] Mann, L. (1992), "Stress, affect, and risk taking", in Yates, J.F. (Ed.), Wiley Series in Human Performance and Cognition. Risk-Taking Behavior, John Wiley \& Sons, pp. 202-230.

[5] Saunders, E.M. Jr (1993), "Stock prices and wall street weather", American Economic Review, Vol. 83, pp. 1337-1345.

[6] Topcu, M. and Gulal, O.S. (2020), "The impact of COVID-19 on emerging stock markets", Finance Research Letters, Vol. 36, p. 101691.

[7] Zhang, D., Hu, M. and Ji, Q. (2020), "Financial markets under the global pandemic of COVID-19", Finance Research Letters, Vol. 36, p. 101528.

[8] Ortmann, R., Pelster, M. and Wengerek, S.T., (2020), "COVID-19 and investor behavior", available at SSRN 3589443. 
ISSN (online): 2581-3048

Volume 5, Issue 11, pp 62-64, November-2021

https://doi.org/10.47001/IRJIET/2021.511011

[9] https://money.usnews.com/investing/investing101/articles/what-to-know-about-tech-investing

[10] https://www.forbes.com/sites/jonathanponciano/2021/0 5/13/worlds-largest-tech-companies-

2021/?sh=199d0a9369bchttps://www.forbes.com/sites/j onathanponciano/2021/05/13/worlds-largest-techcompanies-

2021/?sh=199d0a9369bchttps://www.forbes.com/sites/j onathanponciano/2021/05/13/worlds-largest-techcompanies-2021/?sh=199d0a9369bc

[11] Gollotto, J.C. and Kim, S. (2003), "Market valuation of Dot Com companies; R\&D versus hype", Managerial Finance, Vol. 29 No. 11, pp. 61-72.

\section{Citation of this Article:}

Jennifer A. Carag, "Soaring Demand on Public Health Innovation through Digitalization due to Pandemic, are Tech Stocks worth Investing?" Published in International Research Journal of Innovations in Engineering and Technology - IRJIET, Volume 5, Issue 11, pp 62-64, November 2021. Article DOI https://doi.org/10.47001/IRJIET/2021.511011 